This is the author's final, peer-reviewed manuscript as accepted for publication. The publisher-formatted version may be available through the publisher's web site or your institution's library.

\title{
Parental bonding may moderate the relationship between parent physical activity and youth physical activity after school
}

David A. Dzewaltowski, Gregory J. Ryan, Richard R. Rosenkranz

\section{How to cite this manuscript}

If you make reference to this version of the manuscript, use the following information:

Dzewaltowski , D.A., Ryan, G.J., \& Rosenkranz, R. R. (2008). Parental bonding may moderate the relationship between parent physical activity and youth physical activity after school. Retrieved from http://krex.ksu.edu

\section{Published Version Information}

Citation: Dzewaltowski , D.A., Ryan, G.J., \& Rosenkranz, R. R. (2008). Parental bonding may moderate the relationship between parent physical activity and youth physical activity after school. Psychology of Sport and Exercise, 9(6), 848-854.

Copyright: Copyright @ 2008 Elsevier Ltd All rights reserved

Digital Object Identifier (DOI): doi:10.1016/j.psychsport.2007.10.004

Publisher's Link: http://www.sciencedirect.com/science/article/pii/S1469029207001082

This item was retrieved from the K-State Research Exchange (K-REx), the institutional repository of Kansas State University. K-REx is available at http://krex.ksu.edu 
Running head: Parent Bonding

Parental Bonding May Moderate the Relationship between

Parent Physical Activity and Youth Physical Activity After School

David A. Dzewaltowski*

Gregory J. Ryan

Richard R. Rosenkranz

Department of Kinesiology

Community Health Institute

Kansas State University

Suggested Citation: Dzewaltowski, D.A., Ryan, G.J. \& Rosenkranz, R.R. (2008). Parental Bonding May Moderate the Relationship between Parent Physical Activity and Youth Physical Activity After School. Psychology of Sport and Exercise, 9(6):848-854.

Note: The lead authors were supported during this project by grant R01 HD37367-01 from the National Institutes of Health (NICHD, NINR, ODP, NIAID).

* To whom correspondence should be addressed:

David A. Dzewaltowski, Ph.D.*

Department of Kinesiology and

Community Health Institute

Natatorium 8

Kansas State University

Manhattan, KS 66506

785-532-7795

E-mail: dadx@ksu.edu

Fax: 785-532-6486 
Parental Bonding May Moderate the Relationship between Parent Physical Activity and Youth Physical Activity After School

Despite evidence showing that physical activity is related to a number of beneficial physical and psychological outcomes in children and adolescents (Ribeiro et al., 2005), many youth are failing to be sufficiently active (Eaton et al., 2006). Childhood and adolescence is a critical developmental period for the promotion of physical activity (Licence, 2004; Philippas \& Lo, 2005). Unfortunately, there is a well-documented decline in physical activity participation by youth as they progress through the school-aged years (Barnett, O'Loughlin, \& Paradis, 2002; Sallis, Prochaska, \& Taylor, 2000). Great numbers of youth may be decreasing from already inadequate physical activity levels to even lower levels over time. In efforts to remedy these shortcomings, and to deal with rapidly escalating levels of obesity (Hedley et al., 2004), public health officials have recently promoted a recommendation that youth should engage in at least 60 minutes of physical activity on most, preferably all, days of the week (U.S. Department of Health and Human Services and U.S. Department of Agriculture, 2005).

Parents can influence the physical activity levels of their children in several ways (Gustafson \& Rhodes, 2006), including parental support (Davison, Downs, \& Birch, 2006; Heitzler, Martin, Duke, \& Huhman, 2006; Raudsepp, 2006; Trost et al., 2003), modeling (Raudsepp, 2006; Trost, Kerr, Ward, \& Pate, 2001) and parent-youth shared physical activity (Heitzler et al., 2006). Although parents have been considered the "key players” in providing the environmental context for some health behaviors (Golan \& Crow, 2004), parents’ own physical activity levels have been inconsistently linked with those of their children (Gustafson \& Rhodes, 2006). Currently, the evidence for parents serving as effective models for the physical activity of youth is equivocal in the literature. One explanation that may account for the lack of consistency 
in a direct relationship between parents' and children's physical activity is that a third variable, a mediator or moderator variable, may specify the mechanism or condition for parents to exert influence on their children (Baron \& Kenny, 1986).

Kimiecik, Horn \& Shurin (1996) developed a family influence model for children’s moderate-to-vigorous physical activity (MVPA). In addition to environmental influences outside the home and demographic and family characteristics, this model suggested that parental beliefs, behaviors, and family processes impact child perceptions and beliefs about MVPA, all of which influence child MVPA. However, this study's results showed children's perceptions of their parents' beliefs about MVPA were unrelated to child MVPA. In similar fashion, Trost and colleagues (2003) tested a conceptual model linking parental physical activity orientations, parental support, and children's self-efficacy with child physical activity. This study's results showed that parental physical activity was not directly linked with child physical activity. Rather, the physical activity, physical activity enjoyment, and physical activity importance of parents influenced parental support, which directly and indirectly impacted child physical activity through child self-efficacy for physical activity. Although physical activity researchers have studied hypothesized mechanisms such as parental encouragement and support, often, those variables have not been examined using statistical designs that test the mediator or moderator hypothesis. With such designs, a more complete understanding of modeling and the ways parents influence youth physical activity behavior may be achieved.

One promising approach to examine social influence and potential links between youth and parent physical activity may be found in the Social Development Model (SDM) which has been used to explain variations in problem behaviors among youth (Catalano \& Hawkins, 1996; Hawkins \& Weis, 1985). While SDM has primarily been applied in the substance abuse and 
delinquency literature, the model is general enough for application to other realms of behavior such as physical activity. Indeed, research indicates that various youth outcomes are influenced by the same sets of mediators and moderators (Catalano, Berglund, Ryan, Lonczak, \& Hawkins, 2004).

According to the Social Development Model, children learn patterns of behavior primarily from socializing agents in the family and at school. As outlined by Fleming, Catalano, Oxford and Harachi (2002), children are socialized through processes involving four constructs: 1) Perception of opportunities for involvement through activities or interactions with others; 2) Actual involvement in activities or interactions; 3) Skills for participation in activities or interactions; and 4) Perceived reinforcement from these activities and interactions. In SDM, these four constructs are in causal order, with greater perception of opportunities for involvement leading to greater actual involvement, building skills and leading to greater reinforcement. When the socializing process is consistent, a social bond of attachment develops between a child and the socializing agent. This social bond may moderate behaviors by strengthening those consistent with the socializing agent's behaviors, or by weakening behaviors not consistent with those of the socializing agent. For example, an adolescent who has high bonding to an alcohol-drinking parent should be more likely to drink alcohol.

Following the Social Development Model, we hypothesized that parent bonding would influence the association between parent physical activity and youth physical activity after school. The period after school represents relatively discretionary time for youth, wherein they may have more personal influence over their activities. Our hypothesis was that youth who are strongly bonded to their parent have after-school physical activity levels similar to their parent, while less bonded youth report after-school physical activity levels less similar to their parent. 
Therefore, the purpose of the present study was to test whether parent-youth bonding may moderate the relationship between perception of parent physical activity and after-school youth physical activity in a sample of elementary students.

\section{Method}

\section{Participants}

Participants were 57 students from a convenience sample of intact elementary and middle school classrooms. School principals and teachers of two classrooms in the local school district were contacted and agreed to allow access to the students. Overall demographics for these schools showed that $80-86 \%$ of students were Caucasian and $23-36 \%$ were eligible for free and reduced lunch status (lower socioeconomic status). There were 25 sixth-grade and 32 seventhgrade students in our sample. Ages ranged from 11 to 13 years, with a mean of 12.4 years. There were 37 girls and 18 boys, comprised of 46 Caucasians (84\%), 4 Asian-Americans, 2 AfricanAmericans, 2 Hispanics, and 1 Native American. Two students did not disclose gender or racial/ethnic information. IRB approval for the study and written parental consent were obtained prior to any assessment.

\section{Procedure}

Students completed the physical activity, bonding surveys, and multiple PDPAR assessments. The surveys were sent home with the student, along with a parental consent form. Completed surveys and signed parental consent forms were returned to teachers, and two registered dieticians helped teachers to administer the PDPAR. Students completed three recalls during a class period on three different days. 


\section{Measures}

Perception of parent physical activity. Students reported their perceptions of physical activity done by their parents, by their best friend, and in the school. Because data for best friend and school are not germane to this study, they are not presented here. Perceptions of physical activity done by the students’ parents were assessed with four items adapted from the Youth Risk Behavior Surveillance Questionnaire (Heath, Pate, \& Pratt, 1993). Internal consistency of this measure was good, $\alpha=.90$. Students reported the number of days during a typical week their mother and father engaged in moderate physical activity (ranging from 0-7 days) and vigorous physical activity (ranging from 0-7 days). Moderate physical activity was defined to be as hard as brisk walking and lasting 30 minutes or more, and vigorous physical activity was defined to be as hard as jogging and lasting for 20 minutes or more. The moderate and vigorous scores for the mother and father were summed separately, and then averaged to create the parental physical activity score (ranging from 0 to 14 days).

Social bonding. Catalano and Hawkins (1996) conceptualized the social bond as resulting from consistent patterns of reinforcing interactions leading to motivation for complying with, and adopting the norms and values of the socializing agent. Students reported their perceptions of bonding with their parents, best friend, and school, though only parental bonding data are used in the present paper. Parental bonding was assessed with six items adapted slightly in wording from Catalano and Hawkins: Three items asked whether students shared their thoughts and feelings with their mother, would like to be like their mother, and felt like their mother really cared about them; Three items asked whether students shared their thoughts and feelings with their father, would like to be like their father, and felt like their father really cared about them. The relevant measures are designed to assess the individual's perceptions of reciprocity between 
their norms and values and the norms and values of the socializing agent, measured on a fivepoint scale (anchors: 1 = strongly agree, 5 = strongly disagree). Scores were averaged and alpha coefficients were calculated ( $\alpha=.84$ ).

Youth physical activity after school. Because after-school time holds much promise for interventions on children's use of discretionary time toward meeting physical activity recommendations, we focused our physical activity measurements only on this period. The Previous-Day Physical Activity Recall (PDPAR) was used to measure the level of youths’ physical activity after school (Weston, Petosa, \& Pate, 1997). This validated recall requires youths to report the type and intensity of activity they engaged in during each half-hour block of time from 3:00 p.m. to 11:30 p.m. of the previous day. Then, each half hour block is assigned a MET value (one MET, metabolic equivalent, is equal to resting energy expenditure) based on the type and intensity of the activity reported (Weston et al., 1997). Activities are coded as MVPA if the assigned MET value is three or greater, and as vigorous physical activity (VPA) if the assigned MET value is six or greater, cutoffs commonly used in research with the PDPAR (Bungum, Dowda, Weston, Trost, \& Pate, 2000; Pate et al., 2005). The recall was completed three times, and data from a minimum of two recalls were used to calculate the average number of half-hour blocks of MVPA and VPA. Tests of the psychometric properties of the PDPAR have shown high test-retest reliability $(\underline{\mathrm{r}}=.98)$ and concurrent validity with motion sensors $(\underline{\mathrm{r}}=$ $.77)$ and heart rate monitors $(\underline{r}=.63)$ among students in grades 7-12 (Weston et al., 1997). In the present study, Intra-class correlation coefficients (ICC) among the multiple PDPAR assessments were ICC $=.64$ and .60 for the MVPA and VPA standards respectively. 


\section{Statistical Analysis}

Descriptive statistics were calculated for all parental variables and youth after-school physical activity scores. Analysis of variance tests were conducted to examine grade and gender differences. Following guidelines for testing the moderation hypothesis in a hierarchical multiple regression framework (Aiken \& West, 1991), the two first-order effects (e.g., the parental physical activity score and the bonding with parents score) were centralized by subtracting the mean across individuals from each individual score, and were entered in the first step of the regression analysis. The product of the centered first-order effects, or interaction (e.g., parental physical activity-centered score $\mathbf{X}$ bonding with parents-centered score), was entered in the second step of the regression. A significant change in $\underline{\mathrm{R}}^{2}$ from the first to the second step of the regression analysis indicated a significant moderator effect. Alpha was set at .05 for all analyses.

\section{Results}

\section{Descriptive statistics}

Youths engaged in $3.46 \pm 2.1$ half-hour blocks of activity $\geq 3$ METs (MVPA) and $1.63 \pm$ 1.8 half-hour blocks of activity $\geq 6$ METs (VPA). Youths reported their parents' physical activity at $5.98 \pm 4.1$ parent-days per week. Additionally, youths reported moderate to high bonding with their parents (2.99 \pm 0.8 on a 5 - point scale).

\section{Gender differences}

There was a significant gender difference for the VPA standard $(\underline{F}(1,51)=9.34, \underline{p}=$ .004 ). Boys reported $2.62 \pm 0.54$ half-hour blocks of VPA, whereas girls reported $1.13 \pm 0.20$ half-hour blocks. No other significant differences were found for the MVPA or VPA standards. No other significant differences were found for the parental bonding or physical activity measures. 
Parent Bonding 9

\section{Direct and moderated relationships}

Table 1 shows the results of the multiple regression analysis testing the moderating effect of parental bonding on the relationship between parental physical activity and youth physical activity. The interaction term, included in the second step of the regression analysis, was significantly related to the MVPA standard $(\beta=.27, \mathrm{t}(53)=2.11, \mathrm{p}=.04)$ and contributed to a significant increase in $\underline{\mathrm{R}}^{2}\left(\Delta \underline{\mathrm{R}}^{2}=.07\right)$, while the overall regression model approached significance $(\underline{F}(3,53)=2.57, \underline{p}=.06)$. None of the other relationships were statistically significant.

Graphical and statistical analyses were used to examine the form of moderator effects tested in this study. Following guidelines by Aiken and West (1991), simple-slope regression lines of youth physical activity scores were created from predicted values of parental physical activity at the mean and \pm one standard deviation of parental bonding scores. Figure 1 shows the graph of simple-slope regression lines for the significant parental bonding moderator effect. The figure demonstrates how the relationship between parental physical activity and youth MVPA changes based on the level of bonding with the parents. The simple slope for high parental bonding was significant $(\beta=.29, \underline{\mathrm{t}}(53)=2.70, \underline{\mathrm{p}}=.009)$, whereas the simple slope for low parental bonding $(\beta=-.01, \underline{\mathrm{t}}(53)=-0.06, \underline{\mathrm{p}}=.95)$ was not.

\section{Discussion}

The results of this study showed age and gender differences in physical activity consistent with previous studies (Sallis et al., 2000), but add a novel element to the literature: Parental bonding may be a moderator of the relationship between parent physical activity and youth physical activity after school. Consistent with hypotheses derived from the Social Development Model, a significant moderator effect was found such that the relationship between 
perception of parental physical activity and youth participation in MVPA after school increased only to the degree that parental bonding increased. Physically active children who were highly bonded with parents would be more likely to perceive opportunities for physical activity, to participate and build skills for physical activity, and to find physical activity participation rewarding. Children highly bonded with parents would adapt their levels of physical activity to be consistent with the socializing parent's behaviors. Our study's finding is similar to previous research showing a facilitative effect for parental influence mechanisms (Trost et al., 2003), though the present study tested physical activity relationships to illustrate clearly the impact that the hypothesized moderator had on the primary relationship.

Strengths of the present study included the novel application of the Social Development Model to the physical activity literature and that bonding, a proposed mechanism of social influence, was assessed via Likert scale, without categorizing the variable through median or quartile splits for ANOVA statistical models. By maintaining continuity, we were able to show a clearer picture of the role the mechanism plays and could use this information to design more appropriate intervention. Our results suggest that interventions could focus on increasing the physical activity levels of the parents whose children report high bonding, or try to increase the parent-youth bonding between physically active parents and their children. An alternate strategy may be to focus more on parental support mechanisms for families without physical activity models or high bonding. Focusing interventions in this way may lead to more effective and efficient use of intervention resources.

While objective physical activity measurement such as accelerometry could inform future work on this topic, a strength of the current study was the use of a validated recall measure that assessed physical activity over multiple days. Too often, researchers rely on a single self-report 
of physical activity when multiple assessments are needed to adequately represent this complex behavior (Baranowski \& de Moor, 2000). Given that measurement error is reduced and reliability is increased in studies using multiple self-reports of physical activity; results garnered from such studies should be more stable than results from studies using single self-reports.

Some study limitations should be noted. First, although gender-specific analysis was warranted given the consistent gender difference found for youth physical activity in the literature, small sample sizes prevented these analyses in the current study. Future work should investigate not only the impact of child gender, but also parent gender and interactions between genders of parent and child. Second, self-report methods of parent and child physical activity levels may have introduced substantial bias to the study. However, studies such as those of Anderson and Wold (1992) and Godin, Shepard, and Colantonio (1986) have illustrated the importance of adolescent perception of parental physical activity. Third, the generalization of our results is very limited due to the nature of our convenience sample drawn from local elementary and middle schools. Future research should expand the scope by using a larger, diverse sample. Fourth, the cross-sectional design of the study does not allow causal inferences to be made, so future work could track variables longitudinally or employ more experimental designs. Given these limitations, results from this study should be viewed as preliminary findings. Additional research is needed to confirm the role bonding plays as a moderator of physical activity levels between parents and youth.

In conclusion, this study provided preliminary evidence explaining the role that bonding may play as a moderator of the relationship between physical activity of parents and youth physical activity after school. Parental physical activity may influence youth physical activity only to the degree at which the youth perceives a significant social bond. Practitioners may be 
able to increase the effective use of social influence in promoting youth physical activity by taking into account the role bonding may play. 
Parent Bonding 13

\section{References}

Aiken, L. S., \& West, S. G. (1991). Multiple Regression: Testing and Interpreting Interactions. Thousand Oaks, CA:)Sage Publications.

Anderssen, N.A., Wold, B. (1992). Parental and Peer Influences on Leisure-Time Physical Activity in Young Adolescents. Research Quarterly for Exercise and Sport, 63(4), 341-348.

Baranowski, T., \& de Moor, C. (2000). How many days was that? Intra-individual variability and physical activity assessment. Research Quarterly for Exercise and Sport, 71(2 Suppl), S74-S78.

Barnett, T. A., O'Loughlin, J., \& Paradis, G. (2002). One- and two-year predictors of decline in physical activity among inner-city schoolchildren. American Journal of Preventive Medicine, 23(2), 121-128.

Baron, R. M., \& Kenny, D. A. (1986). The moderator-mediator variable distinction in social psychological research: Conceptual, strategic, and statistical considerations. Journal of Personality and Social Psychology, 51(6), 1173-1182.

Bungum, T., Dowda, M., Weston, A., Trost, S., \& Pate, R. (2000). Correlates of physical activity in male and female youth. Pediatric Exercise Science, 12, 71-79.

Catalano, R. F., Berglund, M. L., Ryan, J. A. M., Lonczak, H. S., \& Hawkins, J. D. (2004). Positive youth development in the United States: Research findings on evaluations of 
positive youth development programs. The Annals of the American Academy of Political and Social Science, 591(1), 98-124.

Catalano, R. F., \& Hawkins, J. D. (1996). The social development model: A theory of antisocial behavior. Delinquency and Crime: Current Theories, 149-197.

Davison, K. K., Downs, D. S., \& Birch, L. L. (2006). Pathways linking perceived athletic competence and parental support at age 9 years to girls' physical activity at age 11 years. Research Quarterly for Exercise and Sport, 77(1), 23-31.

Eaton, D. K., Kann, L., Kinchen, S., Ross, J., Hawkins, J., \& Harris, W. A., Lowry, R., McManus, T., Chyen, D., Shanklin, S., Lim, C., Grunbaum, J.A., \& Wechsler, H. (2006). Youth risk behavior surveillance- United States, 2005. MMWR Surveillance Summary, 55(5), 1-108.

Fleming, C. B., Catalano, R F., Oxford M. L., \& Harachi T. W. (2002). A Test of Generalizability of the Social Development Model Across Gender and Income Groups with Longitudinal Data from the Elementary School Developmental Period. Journal of Quantitative Criminology, 18(4), 423-439.

Godin, G., Shephard, R.J., Colantonio, A. (1986). Children’s Perception of Parental Exercise: Influence of Sex and Age. Perceptual and Motor Skills, 62, 511-516.

Golan, M., \& Crow, S. (2004). Parents are key players in the prevention and treatment of weightrelated problems. Nutrition Reviews, 62(1), 39-50.

Gustafson, S. L., \& Rhodes, R. E. (2006). Parental correlates of physical activity in children and early adolescents. Sports Medicine, 36(1), 79-97. 
Hawkins, J. D., \& Weis, J. G. (1985). The social development model: An integrated approach to delinquency prevention. The Journal of Primary Prevention, 6(2), 73-97.

Heath, G. W., Pate, R. R., \& Pratt, M. (1993). Measuring physical activity among adolescents. Public Health Reports, 108 Suppl 1, 42-46.

Hedley, A. A., Ogden, C. L., Johnson, C. L., Carroll, M. D., Curtin, L. R., \& Flegal, K. M. (2004). Prevalence of overweight and obesity among US children, adolescents, and adults, 1999-2002. The Journal of the American Medical Association, 291(23), 2847-2850.

Heitzler, C. D., Martin, S. L., Duke, J., \& Huhman, M. (2006). Correlates of physical activity in a national sample of children aged 9-13 years. Preventive Medicine, 42(4), 254-260.

Licence, K. (2004). Promoting and protecting the health of children and young people. Child: Care, Health and Development, 30(6), 623-635.

Pate, R. R., Ward, D. S., Saunders, R. P., Felton, G., Dishman, R. K., \& Dowda, M. (2005). Promotion of physical activity among high-school girls: A randomized controlled trial. American Journal of Public Health, 95(9), 1582-1587.

Philippas, N. G., \& Lo, C. W. (2005). Childhood obesity: Etiology, prevention, and treatment. Nutrition and Clinical Care, 8(2), 77-88.

Raudsepp, L. (2006). The relationship between socio-economic status, parental support and adolescent physical activity. Acta Paediatrica, 95(1), 93-98.

Ribeiro, M. M., Silva, A. G., Santos, N. S., Guazzelle, I., Matos, L. N., Trombetta, I. C., Halpern, A., Negrao, C. E., \& Villares, S. M. (2005). Diet and exercise training restore 
blood pressure and vasodilatory responses during physiological maneuvers in obese children. Circulation, 111(15), 1915-1923.

Sallis, J. F., Prochaska, J. J., \& Taylor, W. C. (2000). A review of correlates of physical activity of children and adolescents. Medicine and Science in Sports and Exercise, 32(5), 963-975.

Trost, S. G., Kerr, L. M., Ward, D. S., \& Pate, R. R. (2001). Physical activity and determinants of physical activity in obese and non-obese children. International Journal of Obesity and Related Metabolic Disorders, 25(6), 822-829.

Trost, S. G., Sallis, J. F., Pate, R. R., Freedson, P. S., Taylor, W. C., \& Dowda, M. (2003). Evaluating a model of parental influence on youth physical activity. American Journal of Preventive Medicine, 25(4), 277-282.

U.S. Department of Health and Human Services and U.S. Department of Agriculture (2005). Dietary Guidelines for Americans (6th Ed.). Washington, D.C.: U.S. Government Printing Office.

Weston, A. T., Petosa, R., \& Pate, R. R. (1997). Validation of an instrument for measurement of physical activity in youth. Medicine and Science in Sports and Exercise, 29(1), 138-143. 
Table 1

Hierarchical multiple regression analyses testing the relationship between youth moderate-to$\underline{\text { vigorous physical activity and parental variables }}$

\begin{tabular}{|c|c|c|c|}
\hline Variable & $\beta$ & $\underline{\mathrm{R}}^{2}$ & $\Delta \underline{\mathrm{R}}^{2}$ \\
\hline \multicolumn{4}{|l|}{ Step 1} \\
\hline Parental physical activity & .22 & & \\
\hline Parental bonding & .02 & .05 & \\
\hline \multicolumn{4}{|l|}{ Step 2} \\
\hline Parental physical activity $\mathrm{X}$ parental bonding & $.27 *$ & .12 & $.07 *$ \\
\hline
\end{tabular}

Note. $\beta$ indicates standardized regression coefficient; $\underline{\mathrm{R}}^{2}$, multiple correlation squared; and $\Delta \underline{\mathrm{R}}^{2}$, change in the squared multiple correlation.

${ }^{*} \mathrm{p}<.05$. 
Figure Caption- Moderation by Parental Bonding in the Relationship between Parental Physical Activity and Youth Physical Activity After School

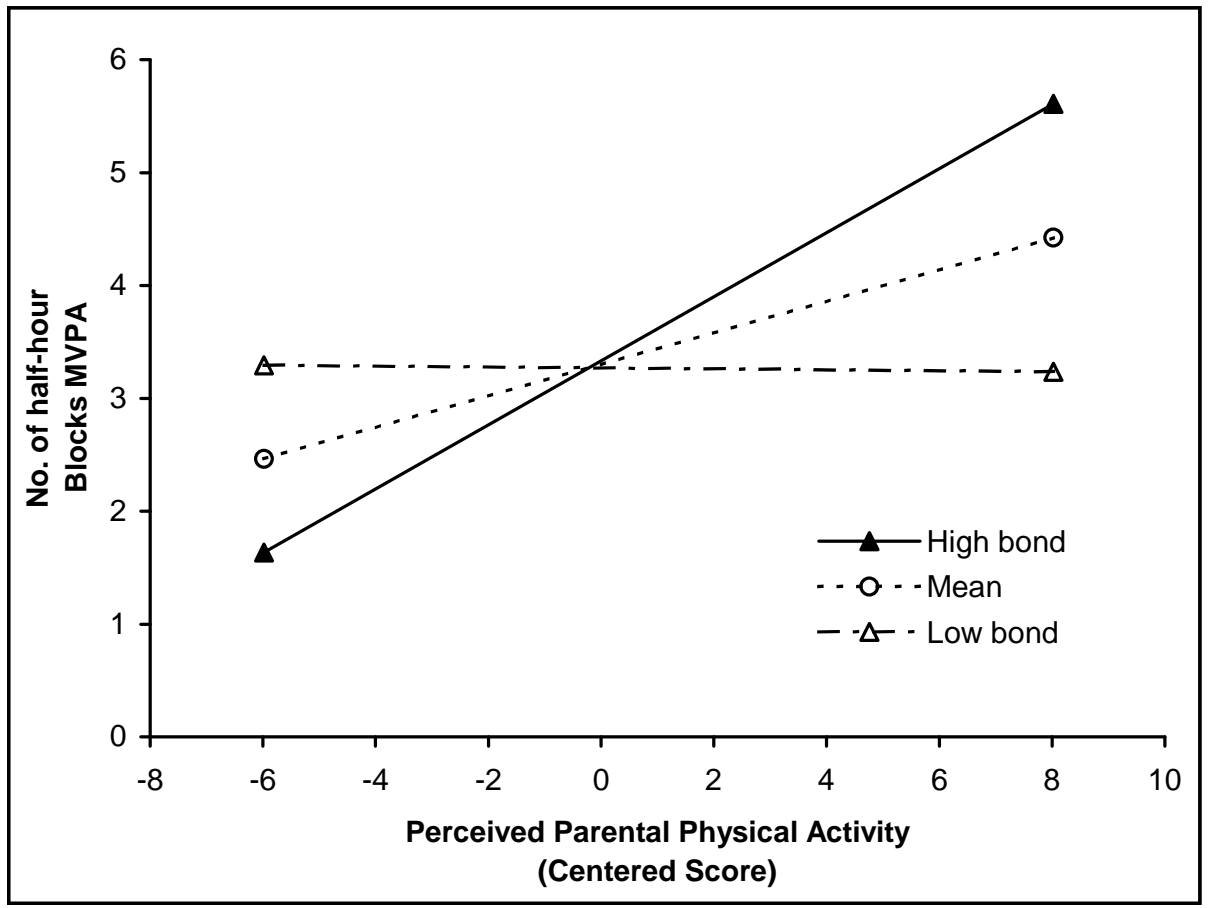

